\title{
PARAMETRIC AND COMPARISON STUDY OF A NEW AND TRADITIONAL ALUMINUM ALLOY JOINT SYSTEMS
}

\author{
Yu-Qi Jiang ${ }^{5}$, Hui-Huan Ma ${ }^{1,2,3,4 *}$, Guang-Tong Zhou ${ }^{5}$ and Feng Fan ${ }^{5}$ \\ ${ }^{1}$ School of Civil Engineering, Sun Yat-Sen University, Guangzhou, PR China \\ ${ }^{2}$ Southern Marine Science and Engineering Guangdong Laboratory (Zhuhai), PR China \\ ${ }^{3}$ Guangdong Key Laboratory of Oceanic Civil Engineering, PR China \\ ${ }^{4}$ Key Laboratory of Building Fire Protection Engineering and Technology of MPS \\ ${ }^{5}$ Harbin Institute of Technology, Harbin, 150090, China \\ * (Corresponding author: E-mail: mahh5@mail.sysu.edu.cn)
}

\section{A B S T RA C T}

Aluminum alloy penetrating (AAP) joint system is a new type of semi-rigid aluminum alloy joint developed by adding a U-shaped connector and a penetrating member to the original Aluminum Alloy Temcor (AAT) joint. For the commonly used aluminum materials in structural engineering, 6061-T6 aluminum alloy, the static out-of-plane bending moment resistance tests of six specimens of the AAP joints are carried out. The failure modes and moment $(\mathrm{M})$-rotation $(\Phi)$ curves of different cover shapes are obtained. Considering the influence of factors such as the contact surface, installation gap and bolt pre-tightening force on the joint, finite element method is used to establish simulation models of AAP joints and AAT joints, and the failure modes and $M-\Phi$ curves are obtained. By comparing the static performance of the two joints, the stiffness and bearing capacity of the new AAP joint are significantly better than the traditional AAT joints. The parameter analysis of the rotational resistance performance of AAP joints and AAT joints under bending moment and different axial tension and pressure is carried out. Comparing the rotation performance of the two joints under different axial forces, the axial tension force is a more unfavorable load for the joints, and the AAP joints perform better than the AAT joints after being subjected to the axial tensile load.

\section{ART I CLE H I S T ORY}

$\begin{array}{ll}\text { Received: } & 25 \text { May } 2020 \\ \text { Revised: } & \text { 5 October } 2020 \\ \text { Accepted: } & 27 \text { October } 2020\end{array}$

\section{K E Y W O R D S}

Aluminum alloy penetrating (AAP) joint;

Aluminum alloy Temcor (AAT) joint;

Moment-rotation curve;

Failure mode;

Rotational resistance performance:

Numerical simulation

\section{Introduction}

The aluminum alloy was first applied to architectural structures in European and American countries in the 1940s. It was widely used because of the unique advantages of aluminum alloy materials [1].Its technology originated from the aerospace industry at the time. China began the application and research of aluminum alloy structures in the 1990s. The use of aluminum in building structures has come a new trend [2]. As a structural material, aluminum is light and corrosion-resistant which has the irreplaceable advantages of other building materials [3]. Meanwhile, aluminum structures have a strong modern feel and convenient construction [4], so it has broad application prospects in large-span landmark buildings such as sports and performance venues [5]. Currently, domestic large-span aluminum space structures are mainly divided into three types: single-layer spherical reticulated shells, bolt-ball jointed grids, and double-layer reticulated shells.

In recent years, with the increasing requirements for the beautiful appearance of buildings, single-layer free-form surface structures have received a growing number of attention, and the requirements for aluminum alloy joints have gradually increased. Based on the traditional requirements of rigidity and bearing capacity, higher requirements have been put forward on the direction angles of spatial connections, installation accuracy and construction speed of aluminum joints [6]. In this regard, research and development of new aluminum joints have been carried out at home and abroad, such as the self-piercing riveted joints [7, 8], T-stub joints [9, 10], aluminum welded connections [11], cast aluminum joints [12]. Research on the aluminum space structures in China started relatively late. Currently, the most widely used joint system is Temcor joint system. Temcor joint is equipped with $\mathrm{H}$-section members. For the mechanical performance of Temcor joint, domestic scholars have conducted a lot of analysis and research. Series of experimental and numerical investigations of Temcor joint in normal and high temperature environments were carried out. [13-23] Zhang [24] carried out a numerical simulation analysis of Temcor joints, and pointed out that the stress of the cover plate was mainly normal stress, which gradually decreased from the middle to the edge. The stress of the member was small and did not yield. The failure mode of the Temcor joints was the bolt yields under shear. Qian [25] proposed that the number of bolts and bolt holes, the size of the cover plate and the amount of arching were important parameters that affected the mechanical performance of the Temcor joints. The lower limit of the cover plate thicknesses of was determined by the thickness of flanges, and the lower limit of the plate diameter was determined by the size of the end of the member. Zou [26] carried out a finite element numerical simulation analysis of Temcor joint, and found that the stress at the contact surface between the cover plates and the numbers was relatively large, but the stress distribution was uniform and reasonable. There was a phenomenon of stress concentration near the bolt holes. The bending stiffness of the joint was calculated out of the joint. It was pointed out that the AAT joint was a semi-rigid joint.

In this paper, based on the traditional AAT joint, the method of adding a $U$ connector and a penetrating member was proposed to develop a new type of aluminum semi-rigid joint, AAP joint. The static rotational resistance performance tests of AAP joints with different gusset shapes and gusset thicknesses under out-of-plane moment were carried out, and the failure modes and M- $\Phi$ curves were obtained. The simulation analysis models of AAP joints and AAT joints corresponding to the experiment were established by using the ABAQUS. The static performance of the two joints, like $M-\Phi$ curves failure modes, was compared. Then, the parameter analysis of the anti-rotation performance of AAP joints and AAT joints considering the influence of axial forces was carried out, and the differences of two joints were analyzed.

\section{AAT joint system and AAP joint system}

Aluminum space structures have prevailed with the application of largespan aluminum roofs, grids, and shells. Because of its poor weldability, aluminum structures are mainly connected by mechanical connections in which the aluminum alloy Temcor (AAT) joint is the most common, as shown in Fig. 1. At present, AAT joint is used in many new single-layer reticulated shell structures in China, for example, the Shanghai Science and Technology Museum built in 2001 is a traditional single-layer aluminum reticulated shells jointed by AAT joints. However, the AAT joint only uses the top and bottom gusset bolts to connect the gusset and the flange, the web of the member is disconnected in the joint region. There are deficiencies such as unclear force transmission path and poor shear resistance performance. 


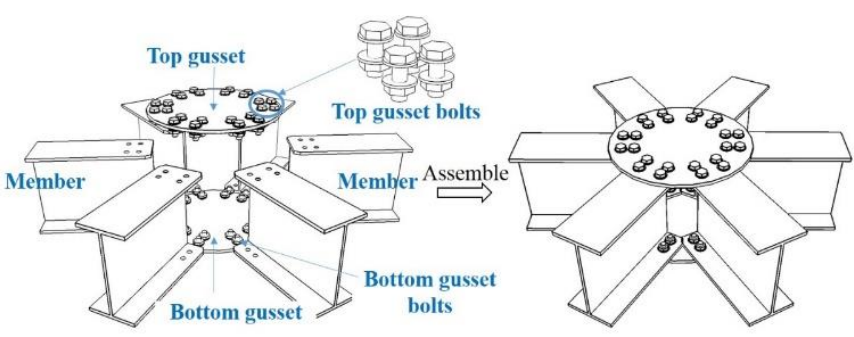

Fig. 1 AAT joint system

Aiming at modifying the disadvantages of the AAT joint in structural and mechanical performance, a new type of semi-rigid aluminum penetrating joint system is designed and developed in this paper, as shown in Fig. 2.The penetration of a joint member has solved the problem of discontinuity of the web in the joint region. At the same time, a U-shaped piece is added to tightly connect the webs of penetrating member and short member. This design improves the overall stiffness and shear resistance of the joint.
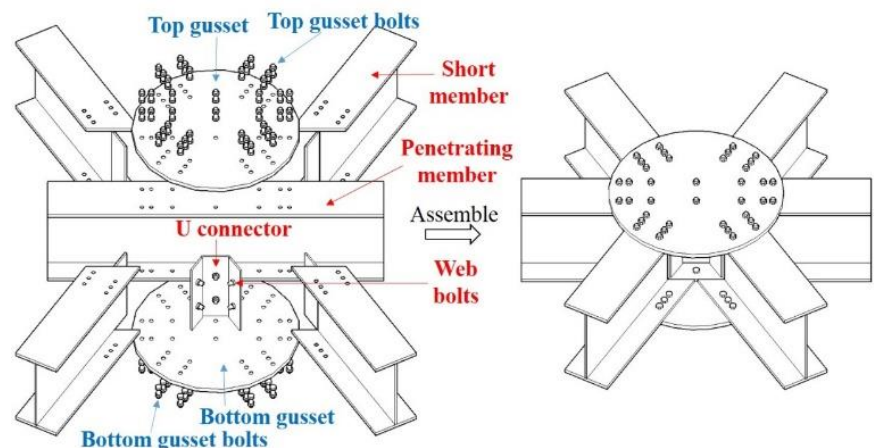

Fig. 2 AAP joint system

\section{Numerical simulation method of joint rotational resistance}

The joint rotational resistance performance is affected by many parameters such as the connection methods, component sizes and bolt forms. Using the large-scale finite element analysis software ABAQUS to analyze the force condition and performance of the joint is a very suitable and efficient method. In this chapter, ABAQUS finite element software was used to establish finite element models of AAP joints and AAP joints corresponding to the test sizes. The stiffness and ultimate bearing capacity of AAT joint and AAP joint were compared, and the difference between the two joints was analyzed.

\subsection{Establishment of numerical models}

The ABAQUS finite element software was used to analyze the mechanical performance of the AAP and AAT joints with $6 \mathrm{~mm}$ and $12 \mathrm{~mm}$ gussets. In order to achieve a comparative study between the finite element analysis (FEA) and test results, the dimensions of numerical models were exactly the same as those of the test specimens, and the dimensions of gussets, members and bolts of AAT models were the same as AAP models. The boundary conditions of the pinned constraints were applied at the ends of the six members, and six equal vertical loads were applied near the gussets to simulate the closest constraint and load conditions to the test. Numerical models of AAP joints used solid elements in ABAQUS, such as the 3D octahedral reduced integral element, C3D8R Element. Based on the three-dimensional octahedral reduction integration, during the meshing process of the joint numerical models, the locations with large stress and obvious deformation were finely meshed to obtain more accurate calculation results, such as bolts of gussets and webs, bolt holes, areas near bolt holes and U-shaped connectors, etc. However, the mesh size in other locations where the joint models had less deformation and stress became larger to increase efficiency. The numerical model was shown in Fig. 3.

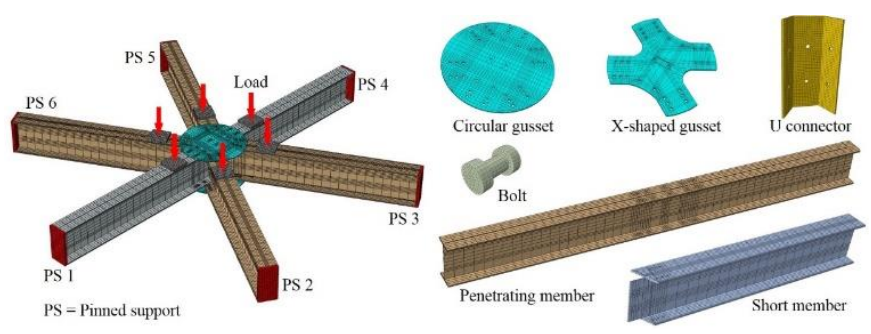

(a) AAP joint model
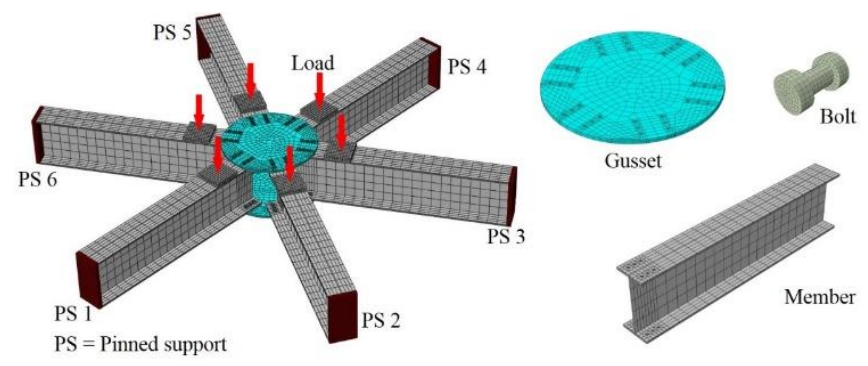

(b) AAT joint model

Fig. 3 Numerical simulation models

The material constitutive model of aluminum members and gusset adopted the classic Ramberg-Osgood aluminum material model. The expected properties of the constitutive model were very close to the actual material properties, so it was widely accepted and used, and its general form was shown in equation (1):

$\varepsilon=\frac{\sigma}{E}+0.2\left(\frac{\sigma}{f_{0.2}}\right)^{n}$

In the above equation, $\sigma$ was the stress of the aluminum alloy, and $\varepsilon$ was the strain corresponding to the stress $\sigma . f_{0.2}$ was the stress value of the residual strain $0.2 \%, E$ was the elastic modulus, and $\mathrm{n}$ is equal to 41.542 . In order to reduce the error between the test and the numerical simulation, the material property data of the aluminum 6061-T6 measured in the material property test was used. Poisson's ratio, $v$, was 0.3 , and density of aluminum, and $\rho_{\mathrm{Al}}$ was $2700 \mathrm{~kg} / \mathrm{m}^{3}$ The model of the bolt material used an ideal elastic-plastic model of stainless steel A4-70 with $f_{0.2}$ equal to $450 \mathrm{MPa}$, elastic modulus, $E$, equal to $200000 \mathrm{MPa}$. Poisson's ratio, $v$, was 0.3 , and density, $\rho_{\mathrm{B}}$ was $7800 \mathrm{~kg} / \mathrm{m}^{3}$.

In non-linear analysis, the surface-to-surface contact needed to be defined in the numerical models. In addition to the contact between gussets and the flanges of the members, the source of the contact pair was mainly from the bolts and the U-shaped connectors, as shown in Fig. 4. A total of 386 contact pairs were provided in one AAP joint, and 300 contact pairs in one AAT joint, as shown in Table 1 below. The tangential action adopted the 'penalty' friction model. Taking into account the relevant provisions of the 'GB50429-2007 Aluminum Alloy Structure Design Code' on the anti-slip coefficient of the friction surface of aluminum alloys, the friction factor of 'penalty' friction in this article was 0.3 .
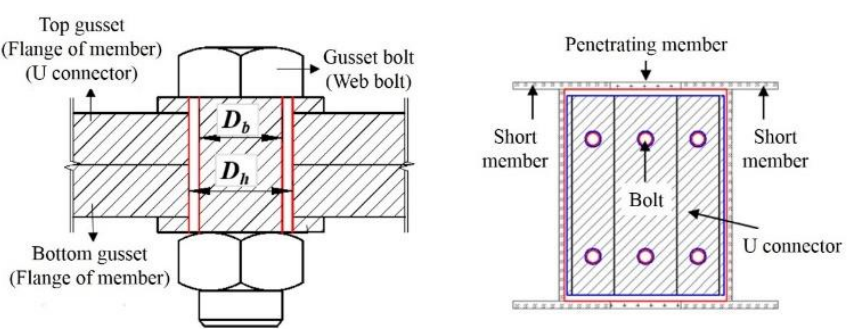

Fig. 4 Diagrams of contact pairs

There were 12 pairs of tie contacts of the AAP joint numerical model, half of which came from the end plates and the end of the member to achieve the pinned connection setting. The other half came from the loading plates and the flanges of members, which applied vertical force to the joint to avoid local buckling failure due to concentrated loads. 
Table 1

Statistics of contact pair

\begin{tabular}{|c|c|c|c|c|c|}
\hline Joint type & Number & Contact type & Master surface & Slave surface & Quantity \\
\hline \multirow{12}{*}{ AAP } & 1 & Surface-surface contact & Gusset & Flange & 10 \\
\hline & 2 & Surface-surface contact & Gusset & Screw & 76 \\
\hline & 3 & Surface-surface contact & Gusset & Nut & 76 \\
\hline & 4 & Surface-surface contact & Flange & Screw & 76 \\
\hline & 5 & Surface-surface contact & Flange & Nut & 76 \\
\hline & 6 & Surface-surface contact & U connector & Screw & 12 \\
\hline & 7 & Surface-surface contact & U connector & Nut & 12 \\
\hline & 8 & Surface-surface contact & Web & Screw & 10 \\
\hline & 9 & Surface-surface contact & Web & Nut & 8 \\
\hline & 10 & Surface-surface contact & U connector & Flange & 4 \\
\hline & 11 & Surface-surface contact & U connector & Web & 6 \\
\hline & 12 & Surface-surface contact & Penetrating & Short & 20 \\
\hline \multirow{7}{*}{ AAT } & Summation & Surface-surface contact & - & - & 386 \\
\hline & 1 & Surface-surface contact & Gusset & Flange & 12 \\
\hline & 2 & Surface-surface contact & Gusset & Screw & 72 \\
\hline & 3 & Surface-surface contact & Gusset & Nut & 72 \\
\hline & 4 & Surface-surface contact & Flange & Screw & 72 \\
\hline & 5 & Surface-surface contact & Flange & nut & 72 \\
\hline & Summation & Surface-surface contact & - & - & 300 \\
\hline
\end{tabular}

In the calculation of the numerical simulation, the pretension force of the bolt was taken into account. Deng Hua [27] used the pressure sensor to test the pretension force of the bolt in the shear test of the ring groove rivet connection of the aluminum alloy plate. The consistent air pressure and working stroke made the pretension force applied to each rivet basically the same. Therefore, the pretension force in this paper used the average value of the pre-tightening force obtained from the above study, $18.85 \mathrm{kN}$.

\subsection{Finite element model validation}

The numerical results were compared with the experimental results to validate their accuracy before the FEA method was applied to the investigation of AAP and AAT joints. The test focused on the rotational resistance performance of 6 specimens of AAP joints which could accurately find out the actual bearing capacity and failure status of the joints. The experimental data such as failure modes and moment-rotation curves of the AAP joint rotating under the out-of-plane moment were obtained to study the stress distribution and force transmission mechanism.

The test device, supports of specimens and connection device were shown in Fig. 5. This test loading device was a 200-ton hydraulic push-pull jack. The hydraulic jack is fixed on the bottom beam of the annular reaction frame. The force sensor was placed between the jack and the distribution beam. The distributive beam is welded by six $\mathrm{H}$-section steel beam, which divided the vertical concentrated force exerted by the jack into six and equally loaded on each member. The $\mathrm{H}$-section members and gussets of the test specimens were made from 6061-T6 aluminum alloy material. U-shaped connectors were made from stainless steel. Each component was connected by Huck bolts. The specific parameter settings of the test piece were shown in Table 2 . This test mainly studied the influence of the gusset thicknesses and shapes on the overall stiffness and ultimate bearing capacity.

Table 2

Specific parameters of specimens

\begin{tabular}{ccccc}
\hline Group number & $\begin{array}{c}\text { Specimen } \\
\text { number }\end{array}$ & Specimens & Gusset shape & Gusset thickness \\
\hline G1 & 2 & G1-1, G1-2 & Circular & $6 \mathrm{~mm}$ \\
G2 & 2 & G2-1, G2-2 & Circular & $12 \mathrm{~mm}$ \\
G3 & 2 & G3-1, G3-2 & X-shaped & $12 \mathrm{~mm}$ \\
\hline
\end{tabular}

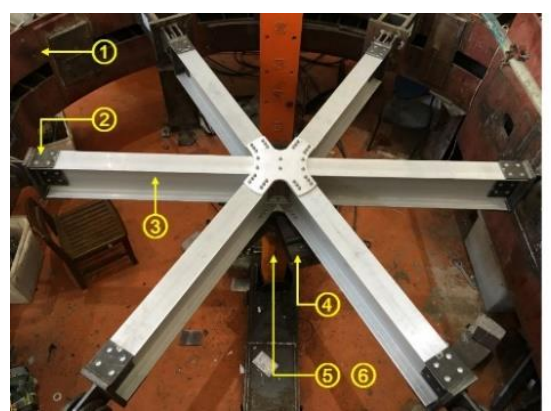

(1) Circular rigid reaction

(2) Pinned connection

(3) Specimen

(4) Distributive beam

(5) Force sensor

(6) Hydraulic jack

Fig. 5 Experimental device

After completing the establishment of the numerical model, the joint was numerically simulated in a bending moment state. The bending $M-\Phi$ curves and stress cloud diagrams at failure stage of the AAP joints obtained from experiments and numerical simulations were shown in Fig. 6 and 7. Further analysis of the $M$ - $\Phi$ curves gained the main characteristic parameters shown in Table 3. It was found that the joint simulation results were close to the test results, with an error of about $4 \%$. It could be considered that the results of and the numerical simulation were accurate and effective.

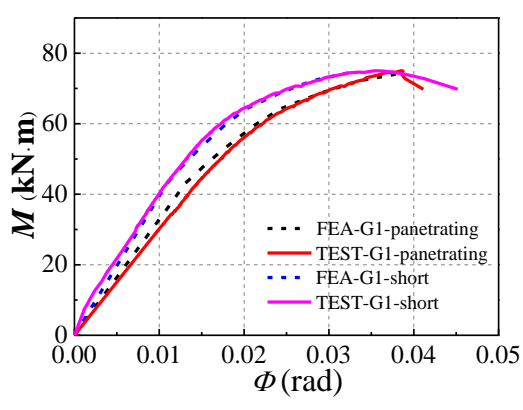

(a) G1 


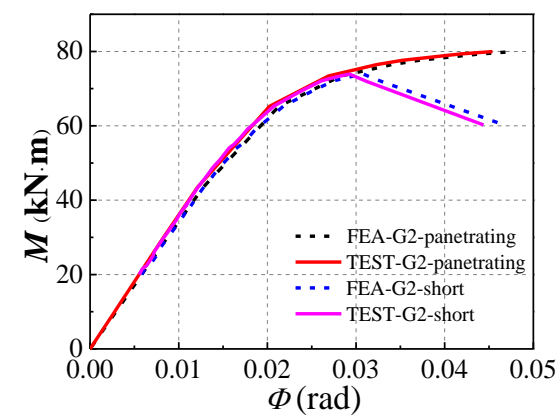

(b) G2

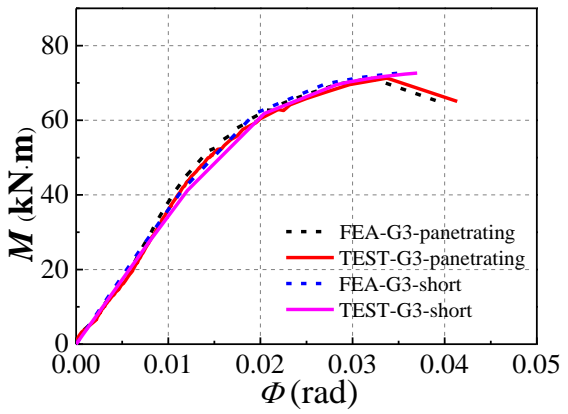

(c) G3

Fig. 6 Comparison of $M-\Phi$ curves of test and numerical simulation results
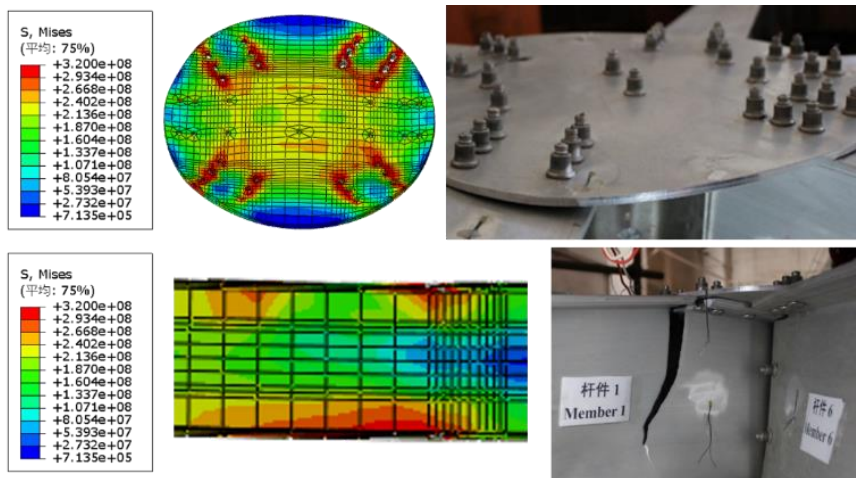

(a) G1
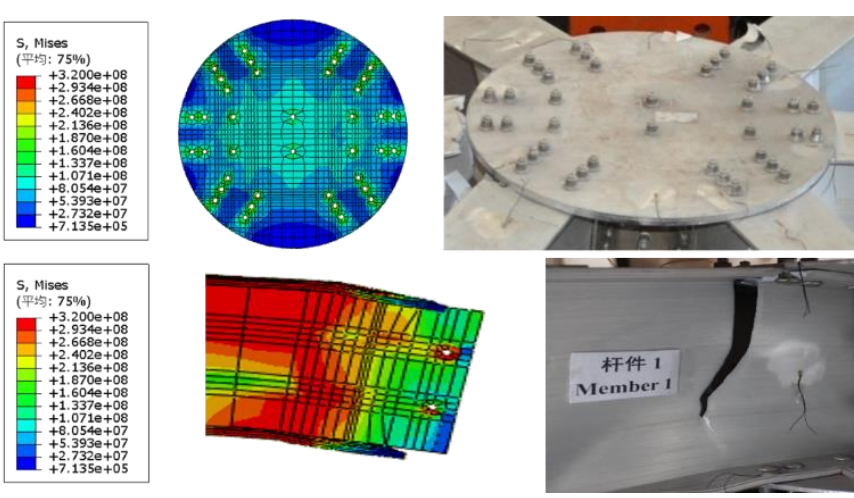

(b) G2
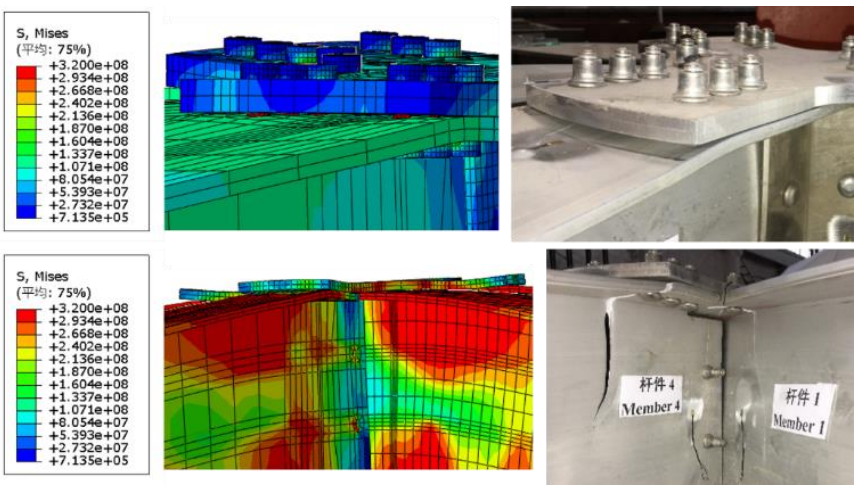

(c) G3

Fig. 7 Failure modes of test and numerical simulation

Table 3

Comparison of results from numerical simulation and test

\begin{tabular}{|c|c|c|c|c|c|c|c|c|c|}
\hline \multirow[t]{2}{*}{ Group number } & \multicolumn{3}{|c|}{$K_{\mathrm{i}}(\mathrm{kN} \cdot \mathrm{m} / \mathrm{rad})$} & \multicolumn{3}{|c|}{$M_{\mathrm{i}}(\mathrm{kN} \cdot \mathrm{m})$} & \multicolumn{3}{|c|}{$M_{\mathrm{u}}(\mathrm{kN} \cdot \mathrm{m})$} \\
\hline & $K_{\mathrm{i}, \text { test }}$ & $K_{\mathrm{i}, \mathrm{FEA}}$ & Error & $M_{\mathrm{i}, \text { test }}$ & $M_{\mathrm{i}, \text { FEA }}$ & Error & $M_{\mathrm{u}, \text { test }}$ & $M_{\mathrm{u}, \mathrm{FEA}}$ & Error \\
\hline G1 & 3163.6 & 3158.5 & $0.2 \%$ & 53.1 & 55.2 & $4.0 \%$ & 71.42 & 72.48 & $1.5 \%$ \\
\hline G2 & 3182.2 & 3175.5 & $0.2 \%$ & 55.2 & 54.7 & $0.9 \%$ & 73.76 & 75.21 & $2.0 \%$ \\
\hline G3 & 3183.5 & 3190.5 & $0.2 \%$ & 54.8 & 53.9 & $1.6 \%$ & 72.15 & 74.28 & $3.0 \%$ \\
\hline
\end{tabular}

\section{Numerical simulation comparison of AAP and AAT joints under beading moment}

As shown in Fig. 8, the comparison curves of the moment-rotation relationship of AAP and AAT joints under pure bending state was analyzed. It could be found that there was a large difference between the moment-rotation curves of the two kinds of joints. From the curve, the AAP joints were significantly better than the AAT joints in terms of initial rotational stiffness and ultimate bearing capacity. The overall change trends of the two types of joint curves were basically the same, and they both had obvious three-stage characteristics. After analyzing the bending moment curves, the main parameters shown in Table 4 were obtained. Analysis of the finite element simulation results of the two types of joints revealed that: (i) the initial rotational stiffness of the AAP joints increased by $38 \%$ compared with the AAT joints when the thickness of the gussets was $12 \mathrm{~mm}$, and the ultimate bearing capacity increased by $47 \%$. (ii) When the thickness of the gussets was $6 \mathrm{~mm}$, compared with the AAT joints, the initial rotational stiffness, $\mathrm{Ki}$, of the penetration members of AAP joints increased by $38 \%$, and $\mathrm{Ki}$ of the short members increased by $20 \%$. The elastic ultimate moment of the joint increased by $70 \%$, and the ultimate moment increased by $90 \%$.

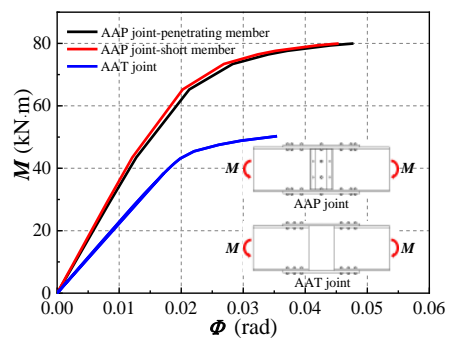


(a) $12 \mathrm{~mm}$ gusset joints

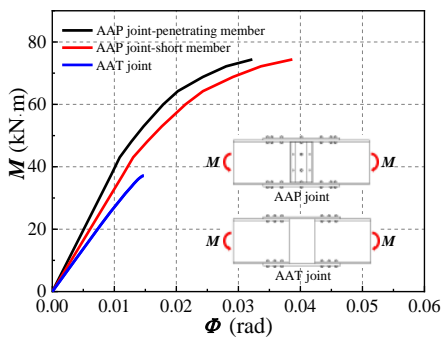

(b) $6 \mathrm{~mm}$ gusset joints

Fig. 8 Comparison of moment-rotation curves of AAP and AAT joints

Table 4

Characteristic parameters of moment-rotation curves of AAP and AAT joints

\begin{tabular}{|c|c|c|c|c|c|}
\hline $\begin{array}{l}\text { Gusset } \\
\text { thickness }\end{array}$ & Joint type & $\begin{array}{c}\text { Member } \\
\text { type }\end{array}$ & $\begin{array}{c}K_{\mathrm{i}} \\
(\mathrm{kN} \cdot \mathrm{m} / \mathrm{rad})\end{array}$ & $\begin{array}{c}M_{\mathrm{i}} \\
(\mathrm{kN} \cdot \mathrm{m})\end{array}$ & $\begin{array}{c}M_{\mathrm{u}} \\
(\mathrm{kN} \cdot \mathrm{m})\end{array}$ \\
\hline \multirow{3}{*}{$t=12 \mathrm{~mm}$} & \multirow{2}{*}{ AAP } & Penetrating & 3181.9 & 54.8 & 72.1 \\
\hline & & Short & 3192.1 & 55.0 & 72.1 \\
\hline & AAT & - & 2291.0 & 30.5 & 48.8 \\
\hline \multirow{3}{*}{$t=6 \mathrm{~mm}$} & \multirow{2}{*}{ AAP } & Penetrating & 3163.9 & 53.6 & 71.2 \\
\hline & & Short & 2766.3 & 53.6 & 71.2 \\
\hline & AAT & - & 2291.0 & 31.4 & 37.1 \\
\hline
\end{tabular}

To further compare the differences in the performance of the two types of joints, the case where the two joints were subjected to the same load was selected, as shown in Fig. 9. When the joints with $12 \mathrm{~mm}$ gussets were subjected to a bending moment of $45 \mathrm{kN} \cdot \mathrm{m}$ (the joints with $6 \mathrm{~mm}$ gussets were subjected to a bending moment of $35 \mathrm{kN} \cdot \mathrm{m}$ ), the AAT joint has basically entered the yield stage, and the stress in the area around the outermost bolt holes of the member has exceeded the yield stress. The overall stress value of the AAP joint was relatively low. Except for the high stress value around the bolt holes, there was basically no region in the plastic stage, and most parts of the H-shaped aluminum members were still in the elastic stage. Especially, the stress value of the web in the central area of the penetrating member was significantly lower. The bending moment on the member transferred to the web of penetrating member through the bolts. The penetrating web shared the load, thereby reduced the stress on the other components. Comparing the gussets of the two joints, under the same external load, most of the stress values of the AAT gusset were greater than the AAP gusset. The stress diagram of AAP joint gusset also proved that the X-shaped gusset had some significance, like reducing the use of materials in areas with less stress and avoiding excessive use of materials.
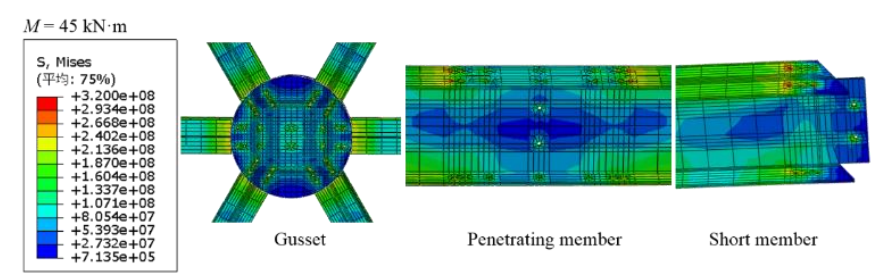

Penetrating member

Short member

(a) AAP joint with $12 \mathrm{~mm}$ gussets
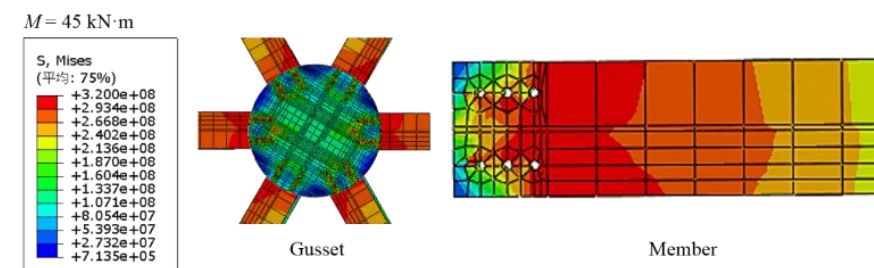

Gusset

Member
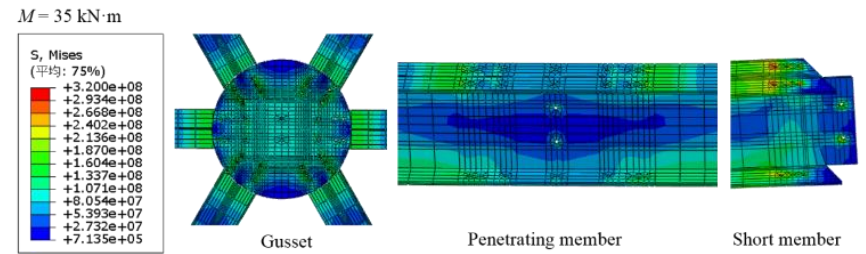

Penetrating member

Short member

(c) AAP joint with $6 \mathrm{~mm}$ gussets
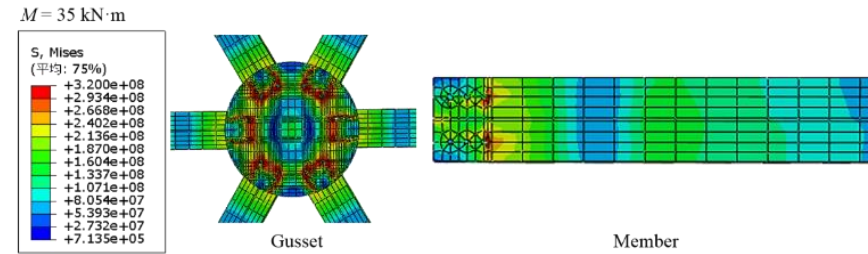

(d) AAT joint with $6 \mathrm{~mm}$ gussets

Fig. 9 Failure modes of AAP and AAT joints

Comparing the rotation resistance performance of the AAP and AAT joints under out-of-plan bending state, the AAT joint failure modes was the tear failure of the members. This was because the flanges and gussets of AAT joints were only connected by bolts and gusset, and the central web was missing. In addition, the thickness of the joint webs was only $5 \mathrm{~mm}$ of which the local stability was weak. Therefore, the finite element results indicated that the webs in the joint area have undergone significant buckling. This proved that the use of the penetrating members and $U$ connectors enhanced the stability of joint area, and solved the problem of the weak connection of the AAT joints in which the members and gussets were connected by bolts. $U$ connector connected the webs of members more closely to avoid buckling or yielding of the webs due to shear stress and local compressive stress. This modification was equivalent to setting web stiffeners in the joint area, thereby the bearing capacity of the joints was effectively improved.

\section{Parameter analysis of rotational resistance performance of AAP and AAT joints considering the influence of axial forces}

5.1. Numerical simulation models of joints considering the influence of axial force

In the actual stress process of the aluminum space structures, the joints are subjected to the combination of bending moments and axial forces, rather than just one of them. Therefore, it is necessary to attach great importance to the performance of joints under the action of forces and bending moments during the design. According to the analysis above, the differences of numerical simulation and test results of AAP and AAT joint are small, so the simulation results are accurate and effective. Numerical simulation methods was adopted in this chapter to continue the analysis and research on the performance of joints under the combination of moments and axial forces, as shown in Fig. 10. Because there is a certain distinction in the joint composition of AAT joints and AAP joints, their mechanical behaviors are different, it is very important to compare the bending performance of AAP and AAT joints with the same geometric parameters under eccentric bending moments. Based on the original joint models, the following adjustments are made in this section: (i) Settings of analysis step: one more step was added between the bolt pretension force and pure bending to apply the axial force load. This setting met the stress state of the joints first receiving the axial force and then the bending moment. (ii) Settings of boundary conditions: When the axial load was applied, only the displacement constraint along the axis of the member was allowed, and the displacement and rotation in other directions were restricted. The boundary conditions in Section 4.1 were maintained when the bending moment was applied. In addition, the basic characteristics of the numerical models including the mesh division, material properties, and bolt pretension are maintained.

(b) AAT joint with $12 \mathrm{~mm}$ gussets 


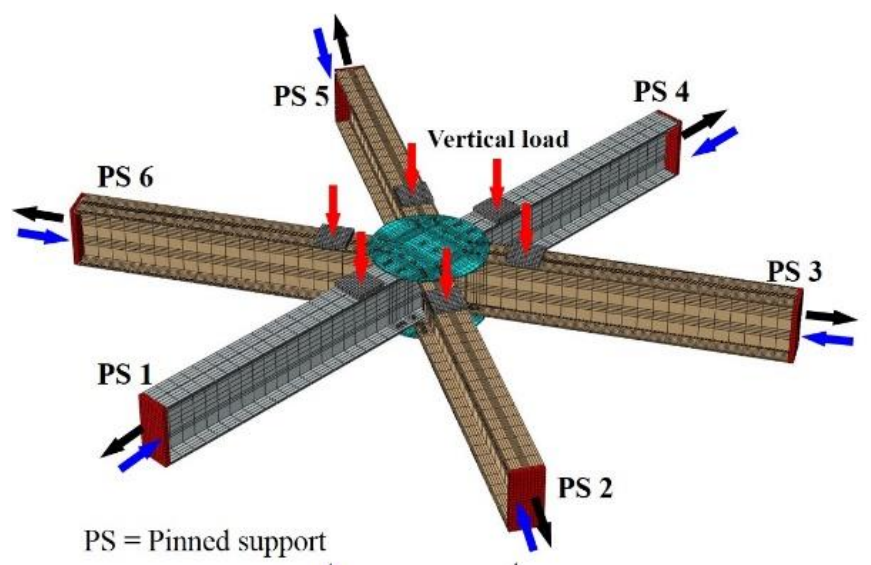

Axial compression (f) and tension (f) force is applied to the PSs.

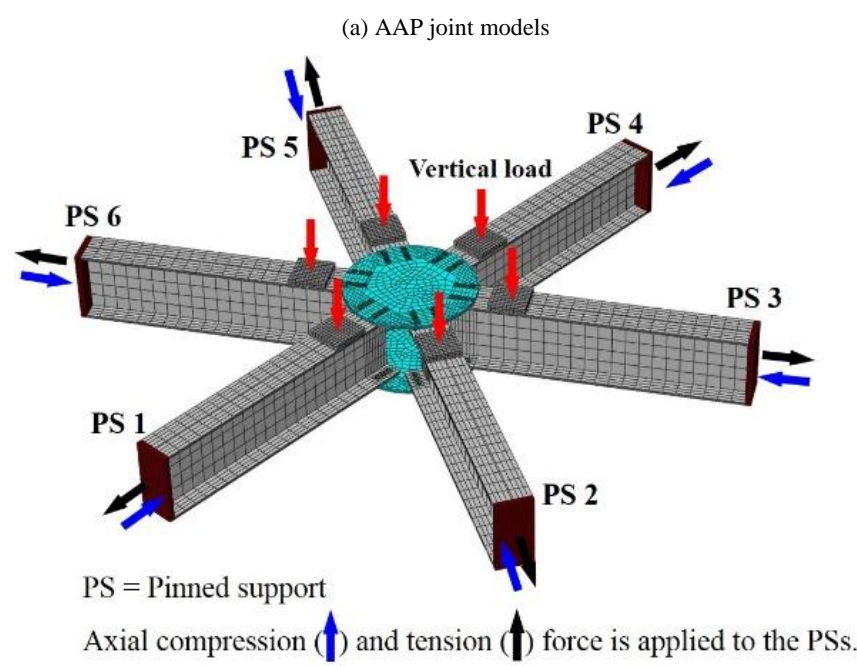

(b) AAT joint models

Fig. 10 Numerical simulation models considering axial forces

\subsection{Rotation resistance performance of $A A P$ and $A A T$ joints under tension and bending moment}

Numerical simulation research on rotation resistance of AAP joints and AAT joints under axial tensile load $\left(N_{\mathrm{t}}\right)$ and out-of-plane bending moment was carried out, because the maximum axial tensile force that the AAP join could withstand when subjected to axial tensile load was $600 \mathrm{kN}$, and the maximum axial tensile load of the AAT joints was $400 \mathrm{kN}$. Therefore, this section studied the rotation resistance performance of the AAP joints and AAT joints after bearing 0 to $600 \mathrm{kN}$ and 0 to $400 \mathrm{kN}$ axial forces, respectively. The momentrotation curves were shown in Fig. 11 below, and further analysis of the $M-\Phi$ curves could obtain the characteristic parameters about the joint performance, as shown in Table 5 below. The results indicated that: (i) as the axial tension increased, the $K_{\mathrm{i}}$ and $M_{\text {sup }}$ of the AAP and AAT joints gradually decreased. (ii) Compared with the short members of the AAP, with the increase of axial tension, the difference in initial rotational stiffness of penetrating members gradually increased. The initial rotational stiffness decreased slowly and then quickly, decreasing only $1 \%$ when the axial tension was $200 \mathrm{kN}$. Then, it decreased $16 \%$ when the axial tension was $400 \mathrm{kN}$. When the $N_{\mathrm{t}}$ reached a maximum of 600 $\mathrm{kN}, K_{\mathrm{i}}$ decreased $33 \%$. The yielding moments of the penetrating members and short members of the AAP were not much different. The descent rate of yielding bending moment was basically maintained at a linear speed. For each increase of $200 \mathrm{kN}$ in axial tension, the yielding moment of the joint reduced by about $20 \%$.

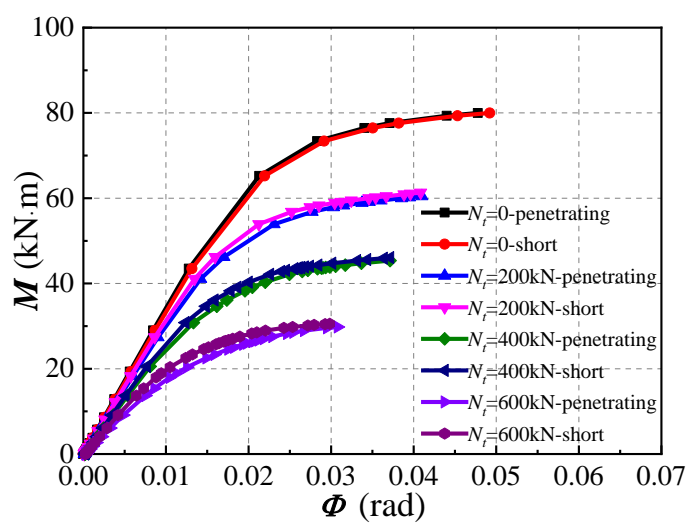

(a) AAP joints

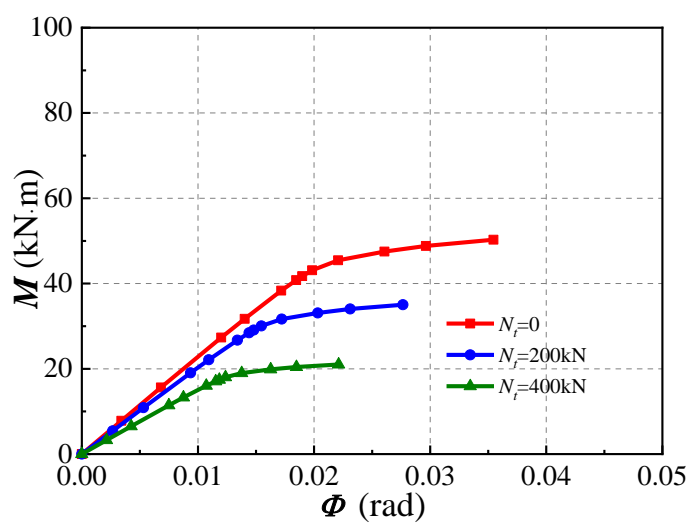

(b) AAT joints

Fig. $11 M-\Phi$ curves of joints under tension and bending

Table 5

The key parameters of AAP and AAT joints under bending moment and tension force

\begin{tabular}{|c|c|c|c|c|c|}
\hline \multirow[t]{2}{*}{ Joint type } & \multicolumn{2}{|c|}{$\begin{array}{c}\text { Axial tension } \\
(\mathrm{kN})\end{array}$} & \multirow{2}{*}{$\begin{array}{c}\text { Stiffness } \\
(\mathrm{kN} \cdot \mathrm{m} / \mathrm{rad}) \\
K_{\mathrm{i}}\end{array}$} & \multicolumn{2}{|c|}{$\begin{array}{c}\text { Moment } \\
(\mathrm{kN} \cdot \mathrm{m})\end{array}$} \\
\hline & & & & $M_{\mathrm{i}}$ & $M_{\mathrm{u}}$ \\
\hline \multirow{8}{*}{ AAP } & 0 & Penetrating & 3181 & 55.0 & 75.6 \\
\hline & & Short & 3179 & 55.0 & 75.6 \\
\hline & 200 & Penetrating & 3161 & 41.1 & 60.2 \\
\hline & & Short & 3042 & 41.1 & 60.2 \\
\hline & 400 & Penetrating & 2679 & 20.6 & 44.7 \\
\hline & & Short & 2554 & 20.6 & 44.7 \\
\hline & 600 & Penetrating & 2139 & 9.1 & 29.6 \\
\hline & & Short & 1822 & 9.1 & 29.6 \\
\hline \multirow{3}{*}{ AAT } & 0 & & 2249 & 31.7 & 50.3 \\
\hline & 200 & & 2003 & 19.0 & 35.0 \\
\hline & 400 & & 1405 & 11.4 & 21.0 \\
\hline
\end{tabular}

The related data parameters of AAP joint were compared laterally with the AAT joint, and the initial rotational stiffness and yield bending moment were plotted in Fig. 12. The figures revealed that: (i) when subjected to tensile and bending loads, the change trend of $\mathrm{Ki}$ and Msup of the AAT joints were the same as those of AAP joint. (ii) AAP joints can bear larger axial load than AAT joints under axial tension. Under the identical axial force, the initial rotational stiffness and yield moment of AAP joints were significantly higher than AAT joint, and the advantage of rotation resistance performance of AAP joints was obvious. 


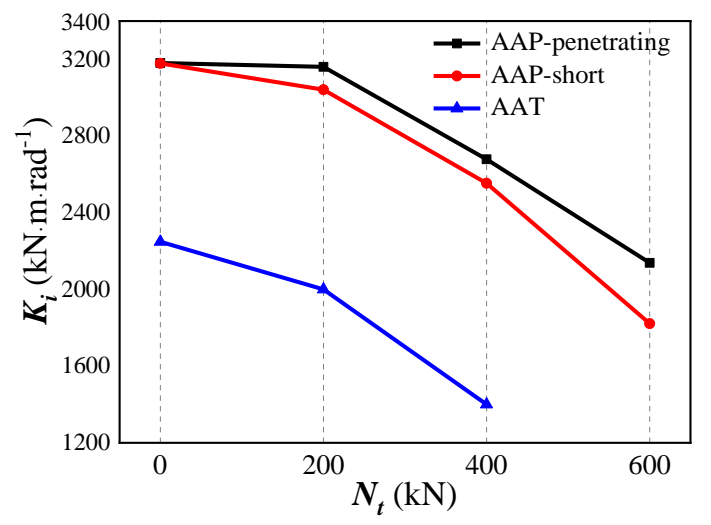

(a) Curves of initial stiffness

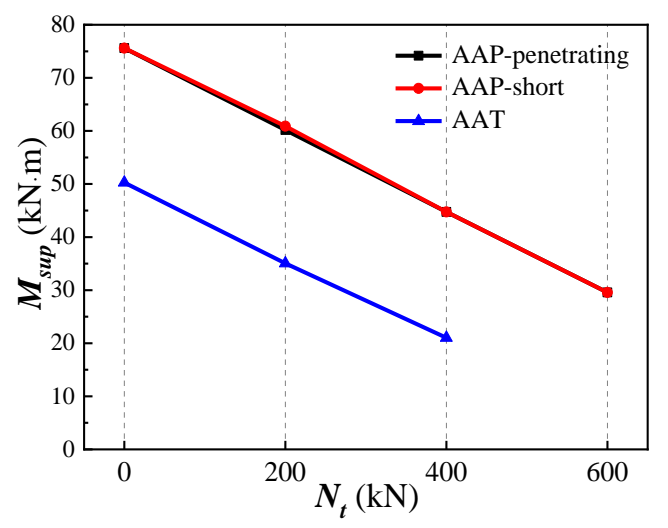

(b) Curves of yield moment

Fig. 12 Curves of Characteristic parameters and axial tension

The failure modes at a pull force of 400kN were shown in Fig. 13 below. In the figure, a small area of the gusset bolts of AAP joints entered yield under the action of axial tension, while a large area of gusset bolts of the AAT entered yield stage, because the only bolts AAT joint resisted shear force. Comparing the two forms of webs, it could be found that under the action of the axial tension load, $\mathrm{U}$ connector played the role of supporting ribs. Although the webs of the penetrating members enterd yielding, the webs deformed little. However, the webs of AAT joints underwent large deformation when the axial force and bending moment were applied.

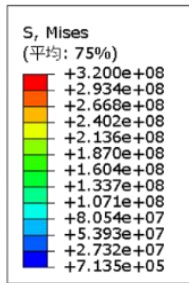

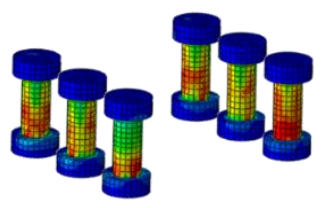

Gusset bolts

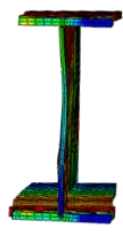

Member

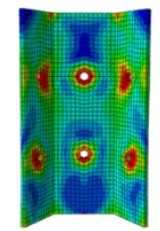

U connector (a) Failure modes of AAP joint

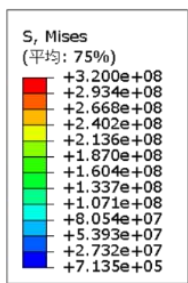

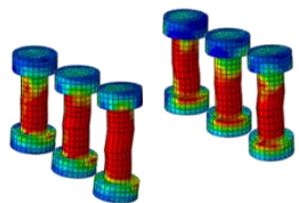

Gusset bolts

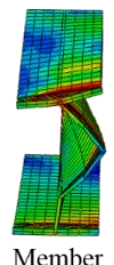

Member (b) Failure modes of AAT join

Fig. 13 Failure modes under tension and bending
5.3. Rotation resistance performance of AAP and AAT joints under compression and bending moment

Numerical simulation research on the rotational resistance of AAP joint and AAT joint under axial compression load $\left(N_{\mathrm{p}}\right)$ and out-of-plane bending load was conducted in this section. Because the maximum axial pressure that the AAP joints could withstand was $900 \mathrm{kN}$, and the maximum axial compressive load of AAT joints was $600 \mathrm{kN}$, so this section studied the rotation resistance performance of AAP joints and AAT joints after bearing 0 to $900 \mathrm{kN}$ and 0 to $600 \mathrm{kN}$ axial pressure, respectively. The moment-rotation curves were shown in Fig. 14 below, and further analysis of curves could obtain the characteristic parameters about the performance, as shown in Table 6 below.

The following conclusions could be drawn: (i) at the axial compression $\mathrm{Np}$ greater than $200 \mathrm{kN}$, the $K_{\mathrm{i}}$ and yielding moment of the AAP joints continued decreasing with the increase of axial pressure. Compared with the short members, the penetrating members of AAP had a slower decrease in initial stiffness and ultimate bending moment as the axial compression increased. (ii) When the axial compression of the AAP joints was less than $800 \mathrm{kN}$, the initial stiffness and yield moment of the joint reduced by about $10 \%$ compared with the pure bending state; but as the joint axial pressure continued to increase to $900 \mathrm{kN}$, the initial stiffness and yield moments had a greater decrease, the degree of decline was saverally $17 \%$ and $40 \%$. (iii) The initial rotational stiffness and yielding moment of the AAT joints decreased as the axial compression increased, and the average degree of decline was greater than that of the AAP joint.

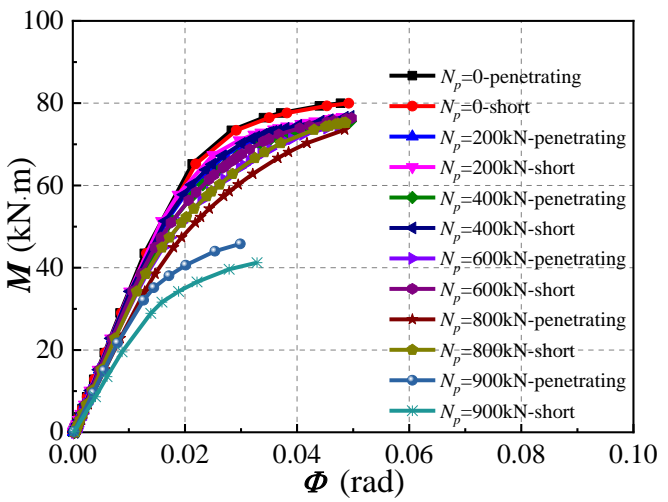

(a) AAP joints

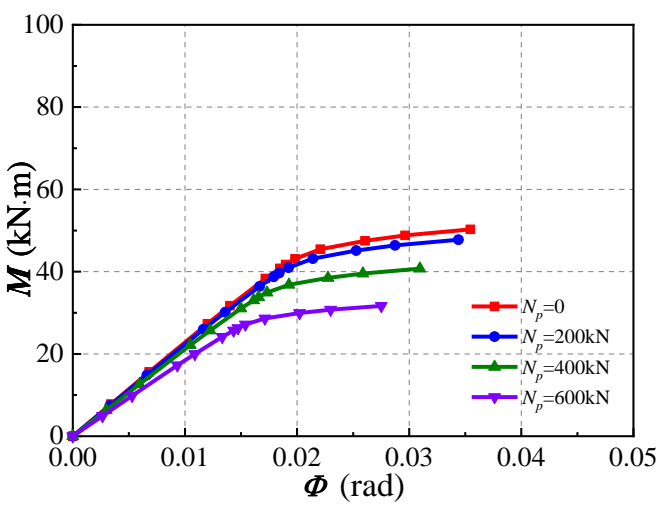

(b) AAT joints

Fig. $14 M-\Phi$ curves of joints under compression and bending

Table 6

The key parameters of AAP and AAT joints under bending and compression

\begin{tabular}{|c|c|c|c|c|c|}
\hline \multirow[t]{2}{*}{ Joint type } & \multicolumn{2}{|c|}{$\begin{array}{c}\text { Axial tension } \\
(\mathrm{kN})\end{array}$} & \multirow{2}{*}{$\begin{array}{c}\text { Stiffness } \\
(\mathrm{kN} \cdot \mathrm{m} / \mathrm{rad}) \\
K_{\mathrm{i}}\end{array}$} & \multicolumn{2}{|c|}{$\begin{array}{c}\text { Moment } \\
(\mathrm{kN} \cdot \mathrm{m})\end{array}$} \\
\hline & & & & $M_{\mathrm{i}}$ & $M_{\mathrm{u}}$ \\
\hline \multirow{5}{*}{ AAP } & 0 & Penetrating & 3181 & 55.0 & 75.6 \\
\hline & & Short & 3179 & 55.0 & 75.6 \\
\hline & 200 & Penetrating & 3280 & 34.2 & 74.8 \\
\hline & & Short & 3277 & 34.2 & 74.6 \\
\hline & 400 & Penetrating & 3169 & 34.2 & 71.9 \\
\hline
\end{tabular}




\begin{tabular}{|c|c|c|c|c|c|}
\hline & \multirow{3}{*}{600} & Short & 3152 & 34.2 & 70.5 \\
\hline & & Penetrating & 3049 & 22.8 & 69.8 \\
\hline & & Short & 2994 & 22.8 & 68.8 \\
\hline & \multirow[t]{2}{*}{800} & Penetrating & 2953 & 22.8 & 68.3 \\
\hline & & Short & 2850 & 22.8 & 65.6 \\
\hline & \multirow[t]{2}{*}{900} & Penetrating & 2666 & 21.0 & 44.0 \\
\hline & & Short & 2223 & 19.6 & 39.6 \\
\hline \multirow{4}{*}{ AAT } & 0 & & 2249 & 31.7 & 50.3 \\
\hline & 200 & & 2197 & 31.0 & 47.7 \\
\hline & 400 & & 2000 & 22.0 & 40.7 \\
\hline & 600 & & 1703 & 17.2 & 31.7 \\
\hline
\end{tabular}

Fig. 15 compared the characteristic parameters of the moment-rotation curves of AAP joints and AAT joints under axial compressive load and bending moment. The Figures revealed that: (i) AAP joints could withstand larger load than AAT joints when subjected to axial compressive load. (ii) When the pressure was less than $200 \mathrm{kN}$, the initial rotational stiffness of the AAP joints slightly increased, and these phenomena did not appeal in the AAT joints. (iii) Under the same axial pressure, the initial rotational stiffness and yield moment of AAP joints were significantly higher than those of AAT joints. (iv) with the increase of $\mathrm{Np}$, the decrease of $\mathrm{Ki}$ and Msup of the AAP joints were significantly slower than those of the AAT joints.

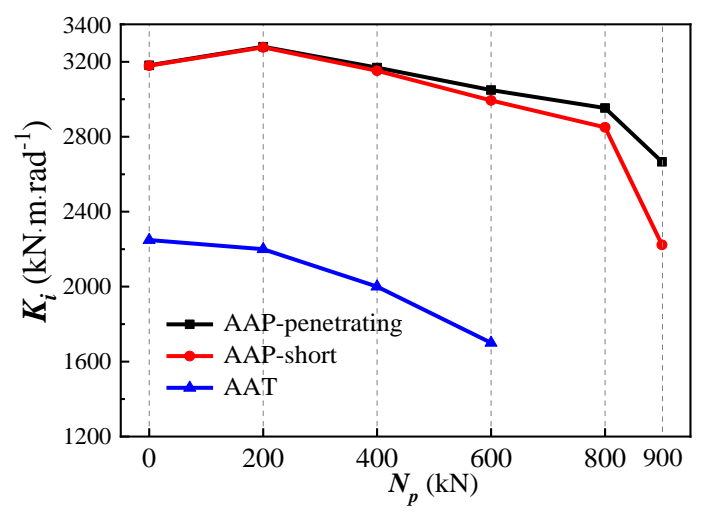

(a) Curves of initial stiffness

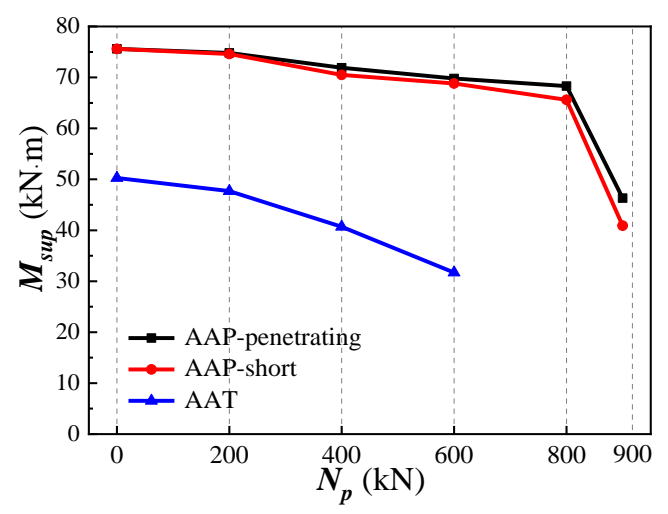

(b) Curves of yield moment

Fig. 15 Curves of Characteristic parameters and axial compression

The failure modes of the AAP joints and the AAT joints under compression were shown in Fig. 16. For the penetrating members of AAP joints, a large area of the web bolts yielded, and the stress value of $\mathrm{U}$ connectors was also very high, yielding around the bolt holes. However, the stress values of gusset bolts and gussets were relatively low. For AAT joints, gussets and gusset bolts entered large-area yielding, and the gussets and webs buckled due to the bending load.

\section{References}

[1] W. M. Doyle, “Aluminum alloys: structure and properties", Metal Science, 35.11, 408,1976. [2] J. Dwight, "Aluminium design and construction", Spon Press, 1999.

[3] R Kissell, "Aluminum Structures - A Guide to Their Specifications and Design", 2002.

[4] F. M. Mazzolani, “Aluminium Structural Design”, Springer Vienna, 2003.
Because the joint of AAT joint was composed of a simple connection between the members and the gussets through the gusset bolts, when the joint was under axial load, the force could only be transmitted by the gusset bolts. During this period, the stress of the webs was small, and not fully utilized. This also caused a significant reduction in the rotational resistance of the AAT joints when subjected to axial force loading. The web bolts of the AAP joints could share a large part of the shear force. Compared with the AAT joints, they were less sensitive to changes in axial pressure and showed higher initial rotational stiffness and yield bending moment.

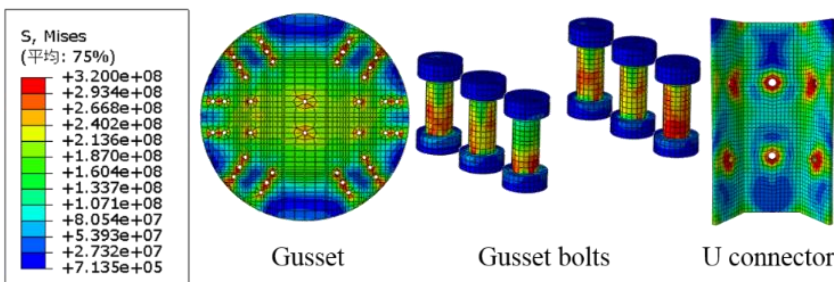

(a) AAP joints
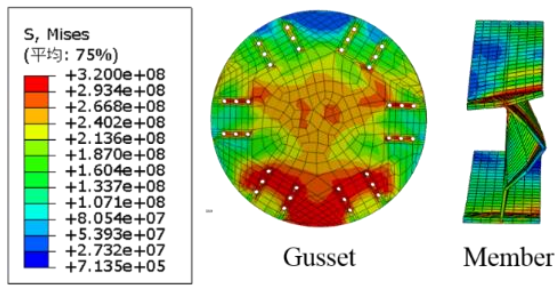

(b) AAT joints

Fig. 16 Failure modes under axial compression and bending

\section{Conclusions}

A new type of semi-rigid AAP joint was developed by adding U-shaped connectors and penetrating members to the original AAT joint. The rotation resistance performance of AAP joints was researched through experiments. The anti-rotation performance of the AAP and AAT joints under pure bending were compared by the numerical simulation method, tension bending and compression bending. The following conclusions were obtained:

(1) Static tests of AAP joints under the out-of-plane moment of different parameters was carried out. The bending rotational resistance performance of the joints were obtained. The moment-rotation curves of penetrating members and short members were defined. The main parameters reflecting the joints' mechanical performance were defined, including the initial bending stiffness $K_{\mathrm{i}}$, initial moment $M_{\mathrm{i}}$, yield stiffness $K_{\mathrm{u}}$ and yield bending moment $M_{\text {sup. }}$.

(2) Comparing the rotation resistance performance of AAP joints and traditional AAT joints in pure bending state, the initial rotational stiffness and yielding moment of AAP joints were significantly improved. The setting of $U$ connector and penetrating members enhanced the connection between the members and gussets.

(3) AAP joints were superior to AAT joints under the combination of axial forces and bending moment. Failure modes of AAP joints were the full-section yield of the members in the joint area, while the failure modes of AAT joints were shear yield of the gusset bolts. Under axial forces, the initial stiffness and yield moment were improved. Meanwhile, it was found that the axial tension was a more unfavorable load for the AAP and AAT joints, and the axial pressure had little effect on the rotational resistance.

\section{Acknowledgements}

This research is supported by The National Science Fund for Distinguished Young Scholars (Grant No. 51525802).

[5] F. M. Mazzolani, “ Structural Applications of Aluminium in Civil Engineering”, Structural Engineering International, 16(4), 280-285, 2006

[6] A. K. Mukhopadhyay, "Selection and Design Principles of Wrought Aluminium Alloys for Structural Applications', Materials Science Forum, 710,50-65, 2012.

[7] N. H. Hoang, A. G. Hanssen, M. Langseth, R. Porcaro, "Structural behaviour of aluminium self-piercing riveted joints: an experimental and numerical investigation", International 
Journal of Solids and Structures, 49 3211-3223, 2012.

[8] L.Han, M.Thornton, M. Shergold, "A comparison of the mechanical behaviour of selfpiercing riveted and resistance spot welded aluminium sheets for the automotive industry", Materials and Design, 31, 1457-1467, 2010.

[9] G.D. Matteis, A. Mandara, F.M. Mazzolani, "T-stub aluminium joints: influence of behavioural parameters", Computers \& Structures, 78, 311-327, 2000

[10] G.D. Matteis, M.T. Naqash, G. Brando, "Effective length of aluminium T-stub connections by parametric analysis", Engineering Structures, 41, 548-561, 2012.

[11] T.K. Chan, R.F.D.P. Goff, "Welded aluminium alloy connections: test results and BS8118", Thin-Walled Structures, 36, 265-287, 2000.

[12] Y.Q. Wang, C. Luo, Y.J. Shi, "Design and research of cast aluminum joint in aluminum alloy spatial structures", International Conference on Electric Technology \& Civil Engineering, IEEE, 2011.

[13] H.H. Ma, F. Fan, P. Wen, H. Zhang, S.Z. Shen, "Experimental and numerical studies on a single-layer cylindrical reticulated shell with semi-rigid joints". Thin-Walled Structures, 86, $1-9,2015$.

[14] H.H. Ma, L. W. Yu, F. Fan, Z. W. Yu, "Mechanical performance of an improved semi-rigid joint system under bending and axial forces for aluminum single-layer reticulated shells", Thin-Walled Structures, 142, 332-339, 2019.

[15] H.H. Ma, Y.Q. Jiang, C. R. Li, Z. W. Yu, F. Fan, "Performance analysis and comparison study of two aluminum alloy joint systems under out-of-plane and in-plane loading. An experimental and numerical investigation", Engineering Structures, 214, 110643, 2020.

[16] H. Liu, Z. Chen, S. Xu, Y. Bu, "Structural behavior of aluminum reticulated shell structures considering semi-rigid and skin effect", Structural Engineering \& Mechanics, 54, 121-133, 2015.

[17] H. Liu, Y. Ding, Z. Chen, "Static stability behavior of aluminum alloy single-layer spherical latticed shell structure with Temcor joints", Thin-Walled Structures, 120, 355-365, 2017.

[18] Z. Xiong, X.N. Guo, Y.F. Luo, S.J. Zhu, Y.P. Liu, "Experimental and numerical studies on single-layer reticulated shells with aluminium alloy gusset joints", Thin-Walled Structures, 118, 124-136, 2017.

[19] Z. Xiong, X.N. Guo, Y.F. Luo, S.J. Zhu, "Elasto-plastic stability of single-layer reticulated shells with aluminium alloy gusset joints", Thin-Walled Structures, 115, 163-175, 2017.

[20] X.N. Guo, Z. Xiong, Y.F. Luo, L.Q. Qiu, J. Liu, "Experimental investigation on the semirigid behaviour of aluminium alloy gusset joints", Thin-Walled Structures, 87, 30-40, 2015.

[21] Z. Xiong, X.N. Guo, Y.F. Luo, H. Xu, "Numerical analysis of aluminium alloy gusset joints subjected to bending moment and axial force", Engineering Structures, 152, 1-13, 2017.

[22] X.N. Guo, S.J. Zhu, X. Liu, L.L. Liu, "Experimental study on hysteretic behavior of aluminum alloy gusset joints", Thin-Walled Structures, 131, 883-901, 2018.

[23] X.N. Guo, S.J. Zhu, X. Liu, K. Wang, "Study on out-of-plane flexural behavior of aluminum alloy gusset joints at elevated temperatures", Thin-Walled Structures, 123, 452-466, 2018.

[24] J. Zhang, J. Zhao, "Analysis of stiffness of gusset-type joints for single-layer reticulated shells", Industrial Construction, 35(4), 88-90, 2005. (In Chinese)

[25] J.H. Qian, P.F. Zhao, C.X. Hao, T. Song, J.D. Zhao, "Development study on large span aluminum alloy dome structure", Building Science, 16(5), 7-12, 2007. (In Chinese)

[26] L. Zou , G. X. Dai, "Finite element analysis of aluminum alloy dome disc cover joints (TEMCOR joints)", National Symposium on Modern Structural Engineering, 638-646, 2009. (In Chinese)

[27] H. Deng, W. Chen, G. Bai, S. Dong, "Experimental study on shearing behavior of lockbolted lap connection for aluminum alloy plates", Journal of Building Structures 37(1), 143-149, 2016. (In Chinese) 